\title{
AC 2008-552: CHARACTERIZING THE ENGINEERING TECHNOLOGISTS: IMPLICATIONS FOR PROGRAM ASSESSMENT
}

\section{Robert Chin, East Carolina University}

Robert A. Chin is a faculty member in the Department of Technology Systems, College of Technology and Computer Science at East Carolina University, where he's taught since 1986. In addition, he is a full member of the East Carolina University and Indiana State University graduate faculties. Chin received his $\mathrm{PhD}$ from the University of Maryland, College Park; MAE from Ball State University; BA from the University of Northern Colorado, and AAS from the Community College of the Air Force. Before joining the ECU faculty, he was on the College of Education faculty at the University of Maryland, College Park. Chin is an active member of ASEE. He has presented numerous papers at annual conferences, FIE, mid-year conferences/meetings, and Southeastern Section meetings. He has had numerous journal articles published including several in the Engineering Design Graphics Journal. He has served as the ASEE's Engineering Design Graphics Division's annual and mid-year conference/meeting program chair, and he is presently a review board member for several journals including the EDGJ. Chin has been a program chair for the Southeastern Section Meeting and has served as the Engineering Design Graphics Division's Vice-Chair and Chair and as the Instructional Unit's Secretary, Vice-Chair, and Chair. 


\title{
Characterizing the Engineering Technologists: Implications for Program Assessment
}

\begin{abstract}
Several sources of instructional and occupational information were examined for their potential to produce and validate statements that describe the expected accomplishments of engineering technology graduates during the first few years after graduation, or objectives, and statements that describe what engineering technology students are expected to know and be able to do upon fulfilling their graduation requirements, or outcomes. The sources examined included crosswalks, the Classification of Instructional Programs, the Occupational Information Network, and the Standard Occupational Classification system. The results indicated that these information sources can serve as valuable and viable adjuncts to other means engineering technology programs use for producing and validating statements that describe the expected accomplishments of engineering technology graduates during the first few years after graduation and that describe what engineering technology students are expected to know and be able to do upon fulfilling their graduation requirements.
\end{abstract}

\section{Introduction}

Engineering technology programs exist to prepare their products, their graduates, to fulfill roles in economic endeavors as technicians or technologists. That is, engineering technology programs exist to prepare their graduates to function effectively in given occupations. As a result, the need to assess the results of the instruction delivered is at the very least a value added step in the instructional process. Instructional programs should be able to identify the standards to which they are teaching and the extent to which their graduates meet those standards.

Most instructional programs seek feedback and respond to the feedback at the course, program, and product performance levels. The standards established by most programs are based on good and well established practices-ie focus groups, advisory boards, surveys, and the like, as are their measurement techniques.

The current literature, however, suggests that engineering technology has not taken advantage of what appears to be a wealth of selected bits instructional and occupational information housed in readily accessible databases. Perhaps it is because the information deals with engineering technology occupations as they are presently rather than what they ought to be or will be. Another reason that could be given is the findings are a result of data that are collapsed from numerous national sources and may not be as applicable to a particular community. The information, never-the-less, appears to be valuable and, at the very least, can serve as an adjunct to what's being used and done.

\section{Purpose}

The purpose of this study was to examine those sources of instructional and occupational information for their potential to produce and validate (a) objectives - statements that describe 
the expected accomplishments of engineering technology graduates during the first few years after graduation and (b) outcomes - statements that describe what engineering technology students are expected to know and be able to do upon fulfilling their graduation requirements. ${ }^{1}$

\section{Occupational Information Network}

The ubiquitous Dictionary of Occupational Titles, ${ }^{2}$ or DOT, was once the principle resource used to match job seekers to jobs based on occupational definitions. The DOT organized jobs by groups call occupations based on similarities and defined the structure and content of all the occupations listed. These definitions were a result of comprehensive studies on how similar jobs were performed in economic endeavors across the nation and were composites of data collected from diverse sources. The term "occupation," as defined by the DOT, referred to this collective description of a number of individual jobs performed, with minor variations, in the economic endeavors surveyed.

While the DOT is still a standard reference in some circles, it has since been replace by the Occupational Information Network or O*NET. ${ }^{3}$ As the replacement for the DOT, O*NET is the nation's primary source of occupational information. It exists to help employers, workers, educators, and students make informed decisions about education, training, career choices, and work. Its existence is realized by a database that contains information on hundreds of standardized and occupation-specific descriptors.

Key to O*NET's effectiveness is the O*NET database. The database, which is available to the public at no cost, is continually updated by surveying a broad range of workers from each occupation. Information from this database forms the heart of $\mathrm{O}^{*} \mathrm{NET}$ OnLine, ${ }^{4}$ an interactive application for exploring and searching occupations.

\section{Standard Occupational Classification}

Embedded in $\mathrm{O}^{*}$ NET are Standard Occupational Classification (SOC) codes, which is one of the means by which $\mathrm{O}^{*}$ NET users negotiate the $\mathrm{O} * \mathrm{NET}$ database. The SOC system is used by federal statistical agencies to classify workers into occupational categories for the purpose of collecting, calculating, or disseminating data. All workers are classified into one of over 820 occupations according to their occupational definition. To facilitate classification, occupations are combined to form 23 major groups, 96 minor groups, and 449 broad occupations. Each broad occupation includes detailed occupation(s) requiring similar job duties, skills, education, or experience. ${ }^{5}$

\section{Classification of Instructional Programs}

The Classification of Instructional Programs, or CIP, is a taxonomic coding scheme that contains titles and descriptions of primarily postsecondary instructional programs that supports the accurate tracking, assessment, and reporting of fields of study and program completion activity. ${ }^{6}$ Virtually all instructional programs are assigned CIP codes, which is the principal means for negotiating the CIP database. 


\section{Crosswalks}

Crosswalks were developed to facilitate the linkage between classification systems. SOC, as an example, is a Bureau of Labor Statistics classification system; CIP, as an example, is a classification system developed by the Department of Education. The National Crosswalk Service Center (NCSC) refers to crosswalks as specialized computer files that are used to relate systems to one another. ${ }^{7}$

Among the crosswalks maintained by NCSC, is the SOC-to-CIP Crosswalks. A result of a joint effort between the Department of Education and the Department of Labor, the purpose of the SOC-to-CIP Crosswalk is to show the relationships between instructional program content and their equivalent Federal Standard Occupational Classification codes, based on the descriptions of each. ${ }^{8}$

\section{Method}

The purpose of this study was to examine several sources of instructional and occupational information for their potential to produce and validate objectives and outcomes. For the purpose of this study, the investigation was limited to industrial engineering technology, as this study's procedures can be applied to other engineering technology programs-ie civil engineering technology, electrical engineering technology, mechanical engineering technology, and the like.

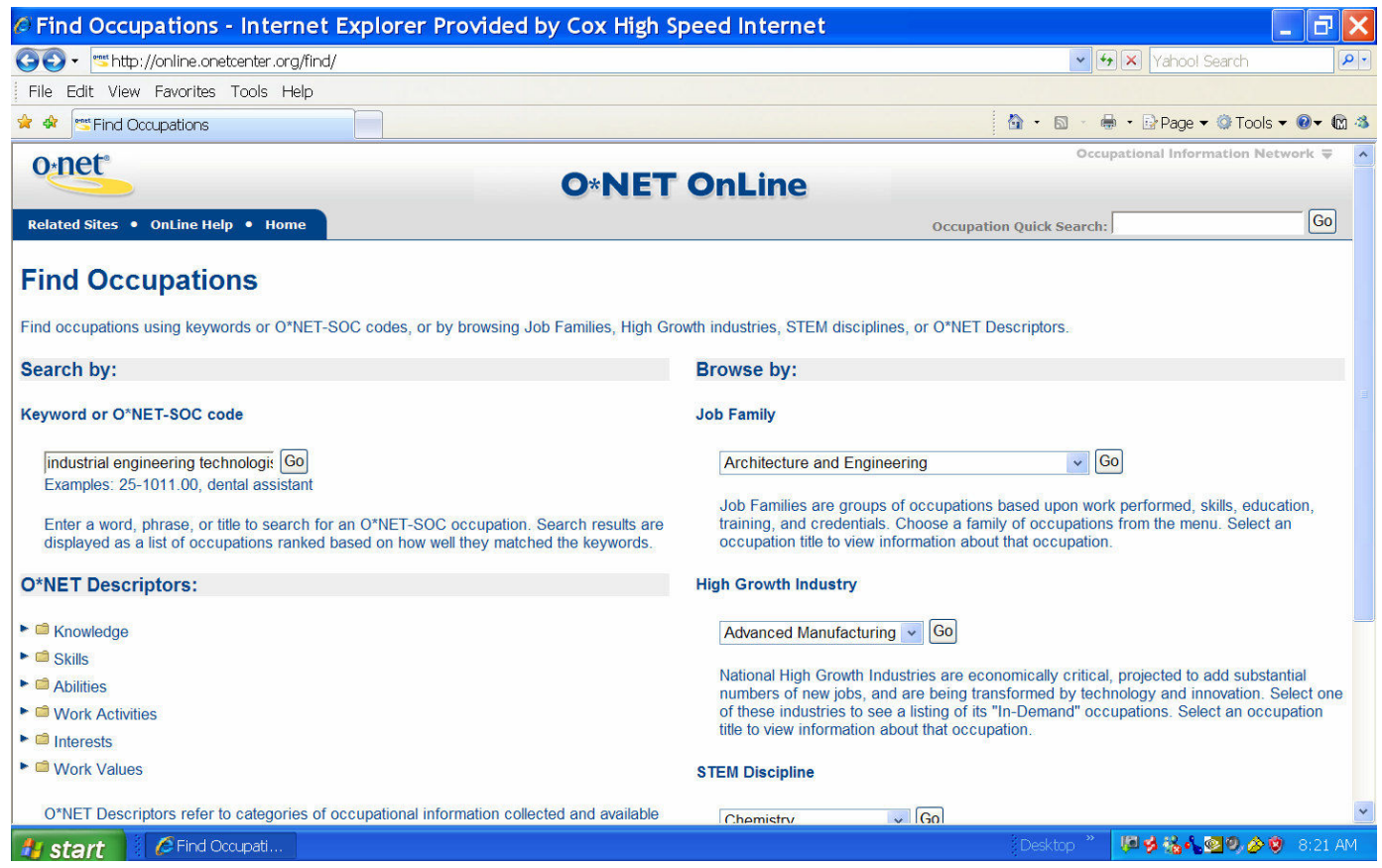

Figure 1. Keyword Search of O*NET OnLine

\section{Procedure}

A keyword search was conducted with the aid of the $\mathrm{O}^{*}$ NET Online ${ }^{9}$ using the phrase "industrial engineering technologist"-see Figure 1. The purpose was to identify the SOC code for 
industrial engineering technologist and its associated occupational information. Once the SOC code and its associated occupational information were identified, the SOC code was used in conjunction with a CIP to SOC Crosswalk ${ }^{10}$ to identify all CIP codes aligned with the industrial engineering technologist SOC code, as an adjunct to this study, and thus all instructional programs associated with the production of industrial engineering technologists.

\section{Results}

The results of an $\mathrm{O} *$ NET OnLine search yielded a list of occupations ranked based on how well they matched the keyword-see Figure 2. Each occupation is provided a relevance score. The search strategy used in the keyword search uses a combination of occupational information, such as associated alternate titles, description, and tasks. A raw score is calculated based on the number of matches across the different data elements and their respective weights. The raw score is then translated to a 0 to 100 relevance ranking.

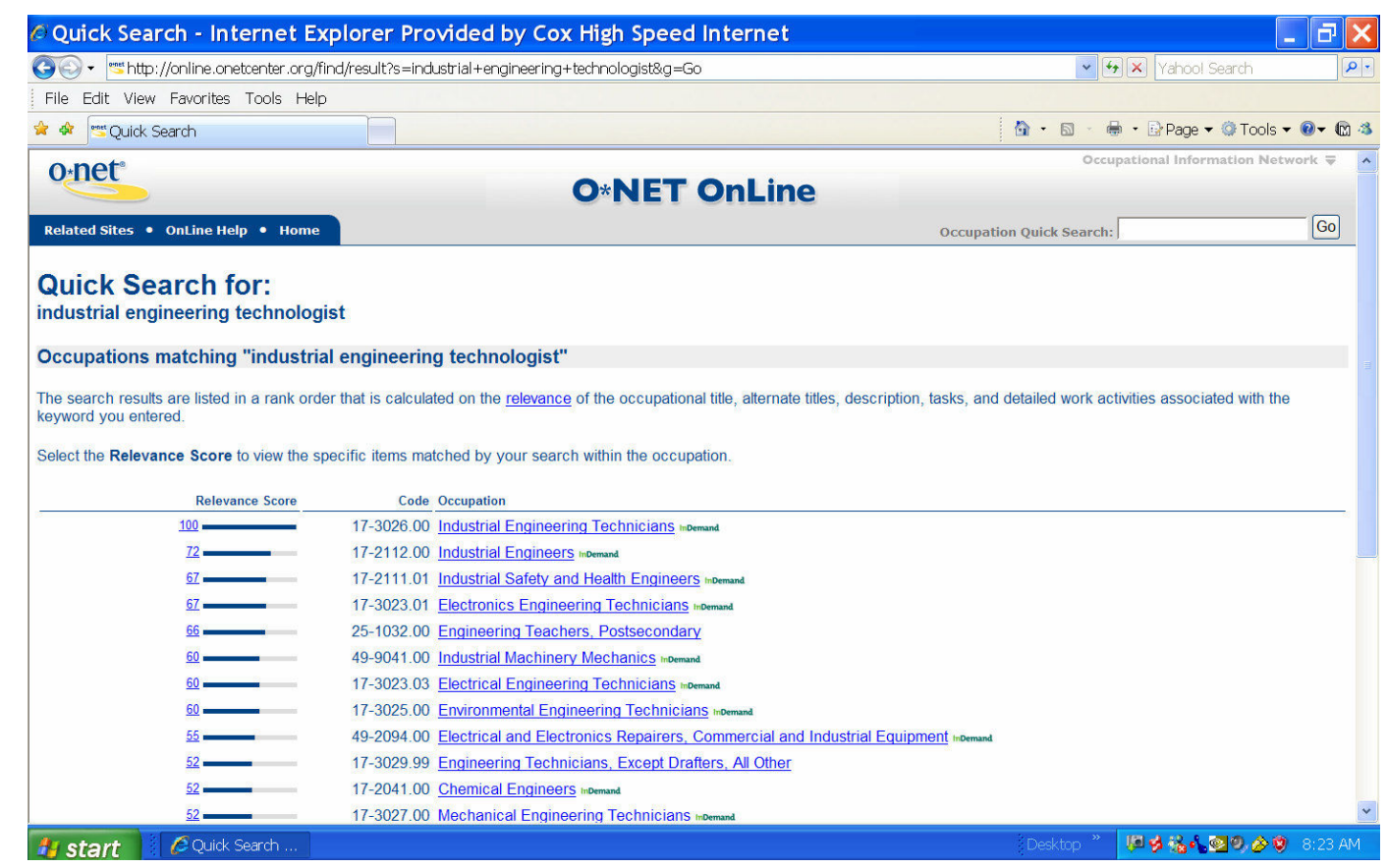

Figure 2. Keyword Search Results

Additional information on any of the occupations listed can be displayed by selecting the respective occupation. For the purpose of this study, the occupation that received a relevance score of 100, was selected. The next relevant occupation, the second in terms of relevance, had a relevance score of 72 .

Once an occupation is selected, the user may exam a summary report, a details report, or produce a custom report by selecting the respective tab-see Figure 3. Summary reports provide the user with the most important descriptors associated with that occupation. Details reports display all descriptors for the occupation selected, definitions of descriptors, and ratings for each descriptor in terms of how important each descriptor is to the occupation. The custom report menu 
provides users with the means for selecting desired descriptor(s), scales, and minimum score levels to include in a report.

\section{The Industrial Engineering Technologists}

For the purpose of this study, selected data were chosen for examination from a summary report produced from the original keyword search on "industrial engineering technologist" - see Figure 3. Specifically, the following were retrieved for examination: (a) Occupation code, title, and definition; (b) Sample of Reported Job Titles; (c) Tasks; (d) Tools and Technology; (e) Knowledge; (f) Skills; (g) Abilities; (h) Work Activities; (i) Work Styles; and (j) Wage data.

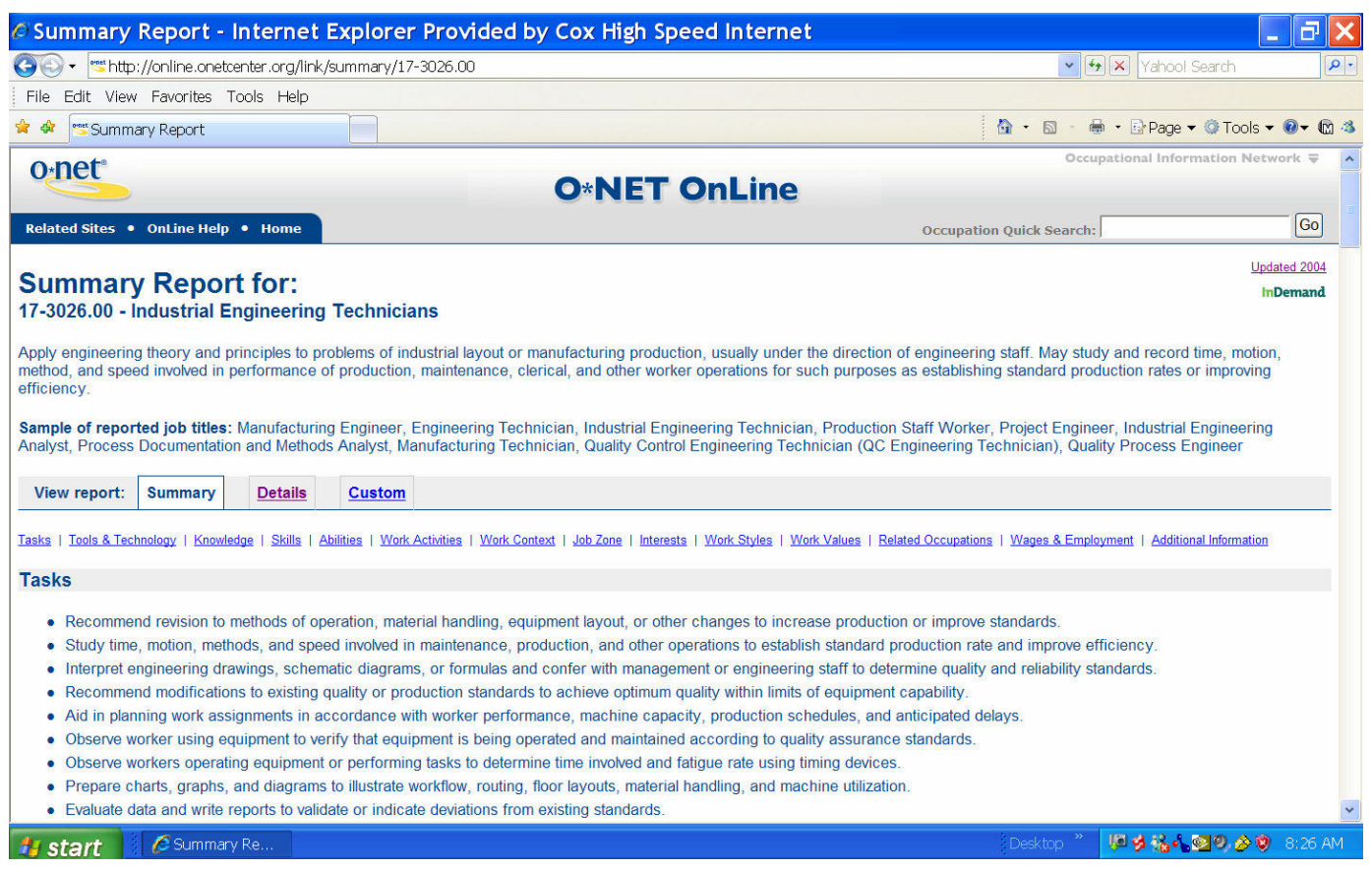

Figure 3. Summary Report

The occupation code, title, and definition were as follows: 17-3026.00; Industrial Engineering Technicians; Apply engineering theory and principles to problems of industrial layout or manufacturing production, usually under the direction of engineering staff. May study and record time, motion, method, and speed involved in performance of production, maintenance, clerical, and other worker operations for such purposes as establishing standard production rates or improving efficiency.

Sample of reported job titles included: Manufacturing Engineer, Engineering Technician, Industrial Engineering Technician, Production Staff Worker, Project Engineer, Industrial Engineering Analyst, Process Documentation and Methods Analyst, Manufacturing Technician, Quality Control Engineering Technician (QC Engineering Technician), Quality Process Engineer.

The specific work activities unique to industrial engineering technologists, or Tasks, are listed in Figure 4. According the details report, these specific work activities are the most important to 
the industrial engineering technologists and are required of industrial engineering technologists.

Recommend revision to methods of operation, material handling, equipment layout, or other changes to increase production or improve
standards.
Study time, motion, methods, and speed involved in maintenance, production, and other operations to establish standard production
rate and improve efficiency.
Interpret engineering drawings, schematic diagrams, or formulas and confer with management or engineering staff to determine quality
and reliability standards.
Recommend modifications to existing quality or production standards to achieve optimum quality within limits of equipment capability.
Aid in planning work assignments in accordance with worker performance, machine capacity, production schedules, and anticipated
delays.
Observe worker using equipment to verify that equipment is being operated and maintained according to quality assurance standards.
Observe workers operating equipment or performing tasks to determine time involved and fatigue rate using timing devices.
Prepare charts, graphs, and diagrams to illustrate workflow, routing, floor layouts, material handling, and machine utilization.
Evaluate data and write reports to validate or indicate deviations from existing standards.
Read worker logs, product processing sheets, and specification sheets, to verify that records adhere to quality assurance specifications.

Figure 4. Tasks

The machines, equipment, tools, and software, or Tools and Technology, an industrial engineering technologists may use are listed in Figure 5.

Tools used in this occupation: Coordinate measuring machines CMM-Direct computer-controlled coordinate measuring machines
DCC-CMM; Forklifts; Gauges or inspection fixtures-Dial indicators; Lathes-Computerized numerical control CNC lathes; Milling
machines-Computerized numerical control CNC milling machines
Technology used in this occupation: Analytical or scientific software-ProMODEL software, Statistical software, Wilcox Associates
PC-DMIS; Computer aided design CAD software-Autodesk AutoCAD, SolidWorks CAD; Data base user interface and query
software-Data entry software, Microsoft Access; Spreadsheet software-Microsoft Excel; Word processing software-Microsoft Word

Figure 5. Tools and Technology

The organized sets of principles and facts that apply to a wide range of situations, or Knowledge, associated with industrial engineering technology are listed in Figure 6. These principles and facts are the most important to and are required of industrial engineering technologists.

Production and Processing (Knowledge of raw materials, production processes, quality control, costs, and other techniques for maximizing the effective manufacture and distribution of goods.)

Engineering and Technology (Knowledge of the practical application of engineering science and technology. This includes applying principles, techniques, procedures, and equipment to the design and production of various goods and services.)

Mathematics (Knowledge of arithmetic, algebra, geometry, calculus, statistics, and their applications.)

English Language( Knowledge of the structure and content of the English language including the meaning and spelling of words, rules of composition, and grammar.)

Clerical (Knowledge of administrative and clerical procedures and systems such as word processing, managing files and records, stenography and transcription, designing forms, and other office procedures and terminology.)

Design (Knowledge of design techniques, tools, and principles involved in production of precision technical plans, blueprints, drawings, and models.)

Computers and Electronics (Knowledge of circuit boards, processors, chips, electronic equipment, and computer hardware and software, including applications and programming.)

Mechanical (Knowledge of machines and tools, including their designs, uses, repair, and maintenance.)

Education and Training (Knowledge of principles and methods for curriculum and training design, teaching and instruction for individuals and groups, and the measurement of training effects.)

Administration and Management (Knowledge of business and management principles involved in strategic planning, resource allocation, human resources modeling, leadership technique, production methods, and coordination of people and resources.)

Figure 6. Knowledge 
The developed capacities that facilitate learning and the performance of activities that occur across industrial engieering technology jobs, or Skills, are listed in Figure 7. These developed capacities are the most important to and are required of industrial engineering technologists.

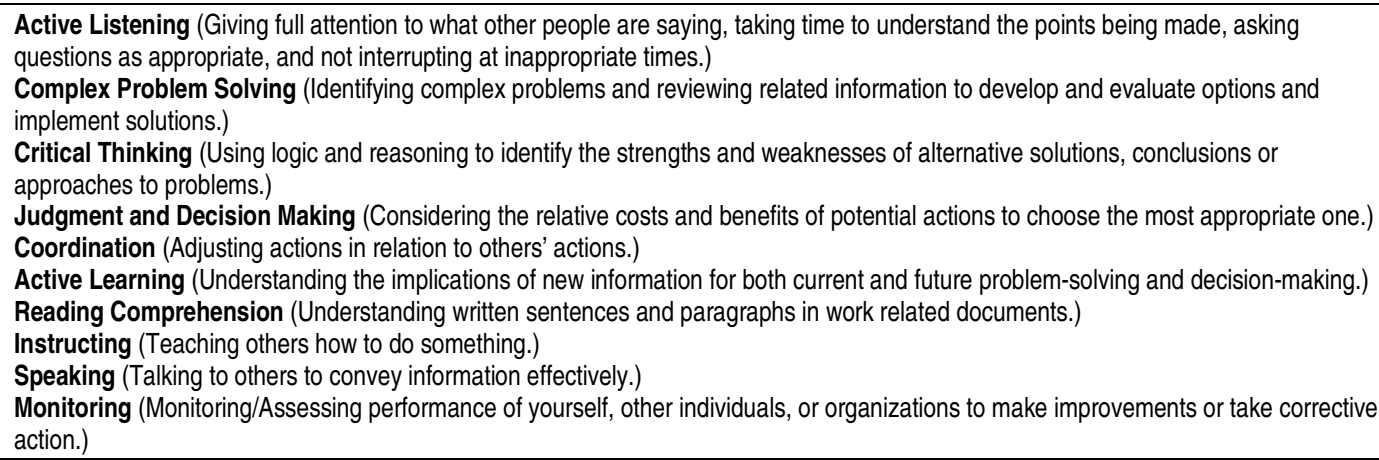

Figure 7. Skills

The enduring attributes that influence performance, or Abilities, of industrial engineering technologists are listed in Figure 8. These enduring attributes are the most important to and are required of industrial engineering technologists.

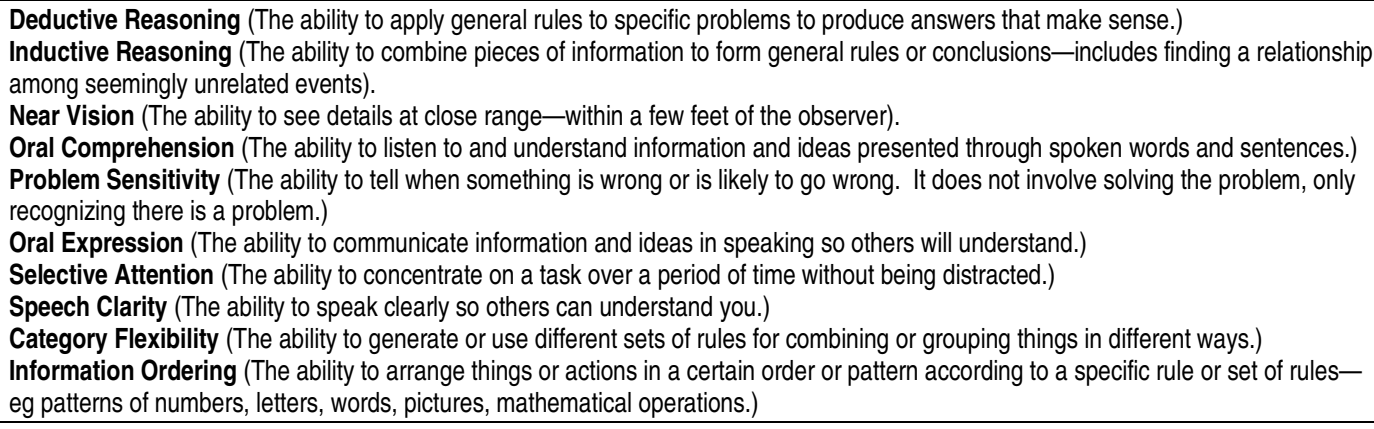

Figure 8. Abilities

The kinds of tasks that may be performed by industrial engineering technologists, or Work Activities, are listed in Figure 9. These kinds of tasks, or Work Activities, are the most important to and are required of industrial engineering technologists. 


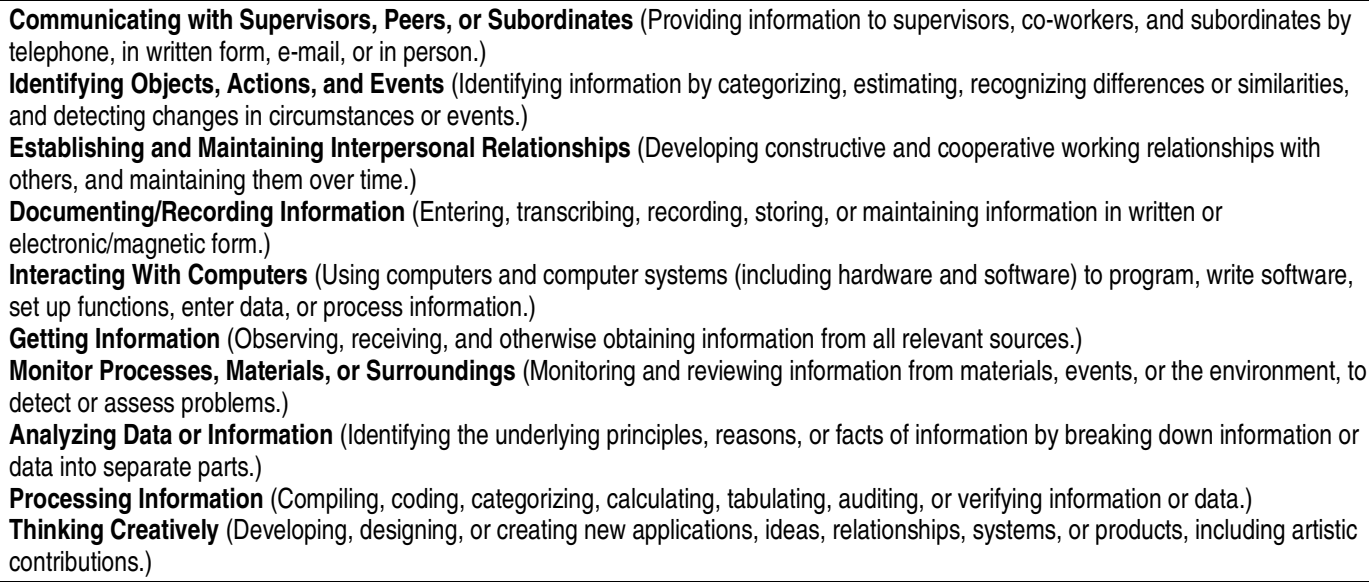

Figure 9. Work Activities

The physical and social factors that influence the nature of work, or Work Context, for industrial engineering technologists are listed in Figure 10.

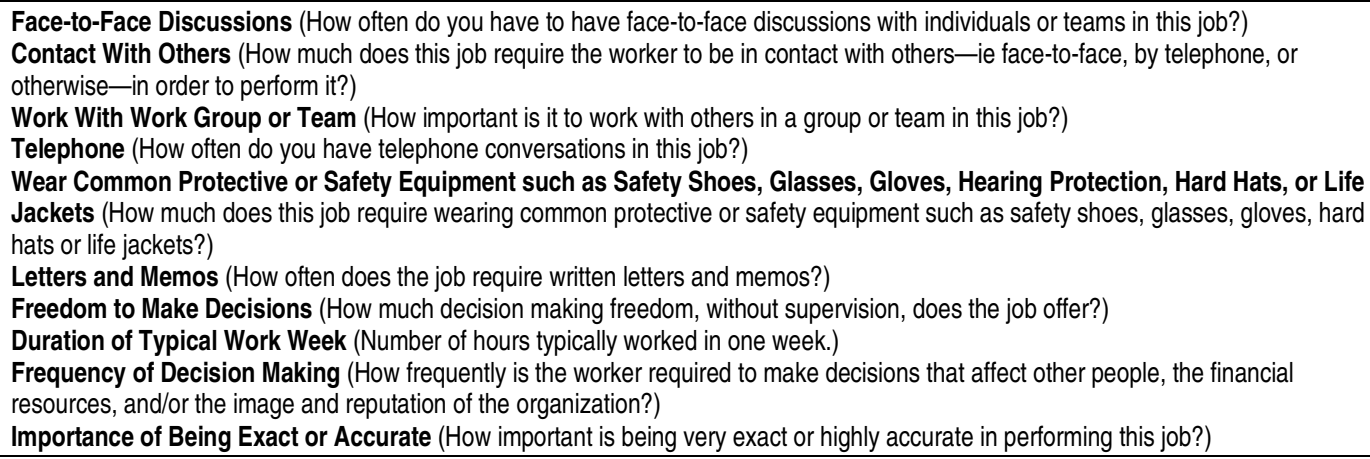

\section{Figure 10. Work Context}

The personal characteristics that can affect how well an industrial engineering technologist does a job, or Work Styles, are listed in Figure 11. These are the most important personal characteristices an industrial engineering technologist can possess.

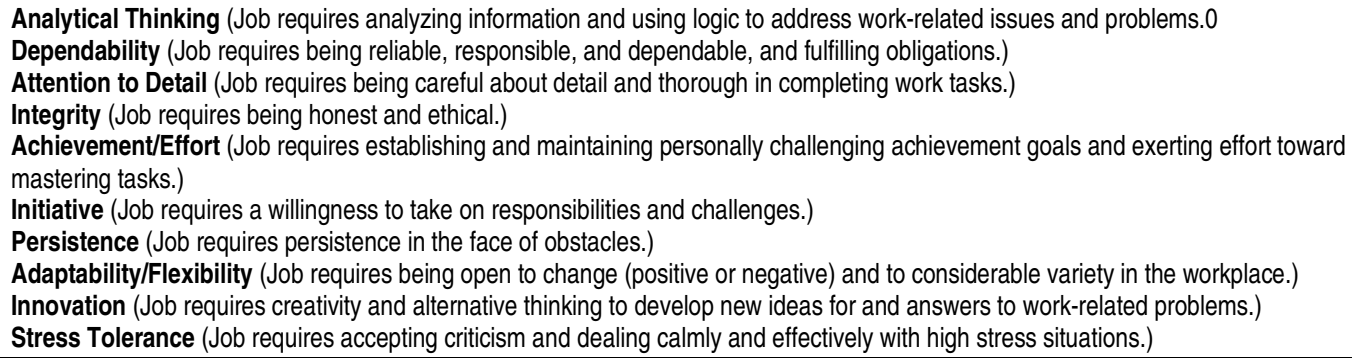

Figure 11. Work Styles 
National wage figures for industrial engineering technologists in 2006 and for industrial engineering technologists in the state of Indiana in 2006 are provided in Table 1. These figures are among data compile and published by the Bureau of Labor Statistics.

\begin{tabular}{llrrrrr}
\hline \multirow{2}{*}{ Location } & & \multicolumn{5}{c}{2006} \\
\cline { 2 - 7 } & Pay Period & \multicolumn{1}{c}{$\mathbf{1 0 \%}$} & \multicolumn{1}{c}{$\mathbf{2 5 \%}$} & \multicolumn{1}{c}{ Median } & \multicolumn{1}{c}{$\mathbf{7 5 \%}$} & \multicolumn{1}{c}{$\mathbf{9 0 \%}$} \\
\hline \multirow{2}{*}{ United States } & Hourly & $\$ 14.52$ & $\$ 17.81$ & $\$ 22.51$ & $\$ 29.26$ & $\$ 38.07$ \\
\cline { 2 - 7 } & Yearly & $\$ 30,200$ & $\$ 37,000$ & $\$ 46,800$ & $\$ 60,900$ & $\$ 79,200$ \\
\hline \multirow{2}{*}{ Indiana } & Hourly & $\$ 14.20$ & $\$ 17.10$ & $\$ 20.68$ & $\$ 25.40$ & $\$ 30.92$ \\
\cline { 2 - 7 } & Yearly & $\$ 29,500$ & $\$ 35,600$ & $\$ 43,000$ & $\$ 52,800$ & $\$ 64,300$ \\
\hline
\end{tabular}

Table 1. Wage Figures for Industrial Engineering Technologists in 2006

\section{SOC to CIP Crosswalk}

A SOC to CIP crosswalk was conducted on the industrial engineering technologist SOC code, 17-3026. The crosswalk yielded the following CIP codes and program titles: 15.0612, Industrial Technology/Technicians; 15.0613, Manufacturing Technology/Technicians; 15.0699, Industrial Production Technologies/Technicians, Others; 15.0702, Quality Control Technology/Technician; 15.0799, Quality Control \& Safety Technologies/Technicians; 15.1501, Engineering/Industrial Management ${ }^{10}$.

\section{Discussion}

\section{SOC to CIP Crosswalk}

Crosswalking can serve as a viable adjunct for validating the intent of instructional programs in engineering technology. A simple item on a questionnaire administered to alumni, as an example, that elicits alumni job titles that, hopefully, match those alternative job titles found in the summary report for industrial engineering technologists, can help validate the intent of an instructional program.

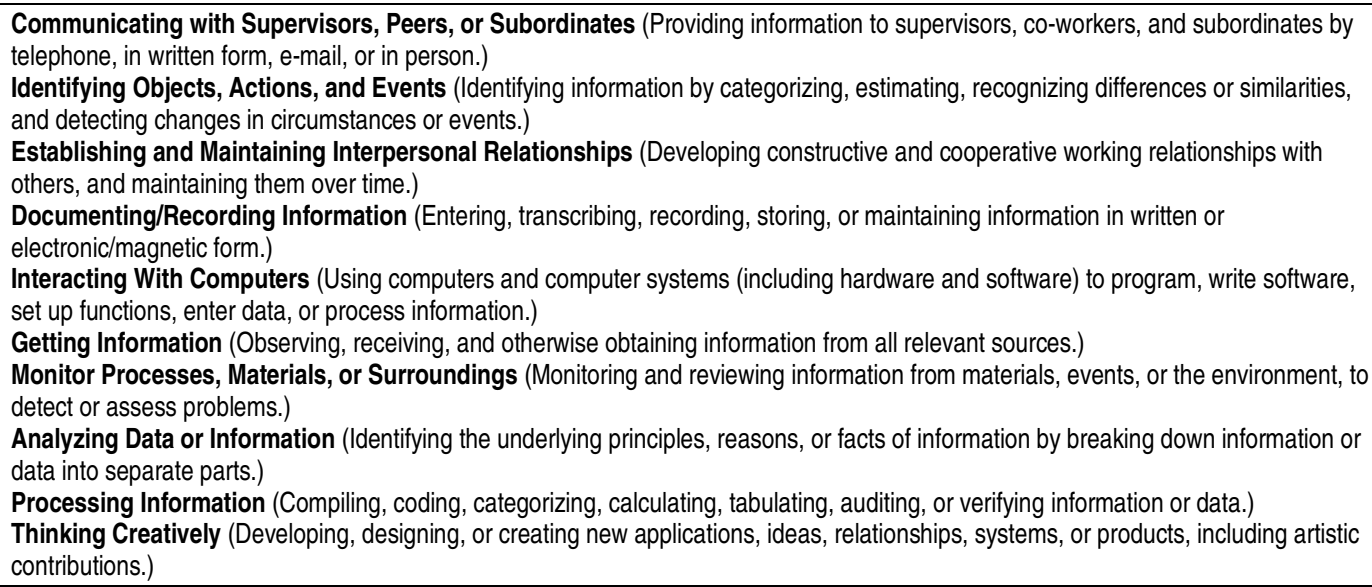

Figure 12. Survey Items Intended to Ascertain Alumni Work Activities 


\section{Occupational Information Network}

A survey of industrial engineering technology alumni, administered within a year or two following graduation, can query program alumni regarding their work activities (see Figure 12) using a Likert Scale. Programs should be asking about the frequency with which alumni engaged in these work activities as they are valid work activities for industrial engineering technologists.

The scale depicted in Figure 13 can solicit the extent to which program alumni are engaged in selected work activities.

Indicate the extent to which you are involved in the following work activities by coloring in the corresponding bubble.
\[ \begin{array}{rrrr}\text { Several times daily } 0 & \text { Once or so daily } 0 & \text { Week } 0 \text { Month } 0 \text { Year } 0\end{array} \]

Figure 13. Sample Likert Scale for Ascertaining Alumni Work Activities

For assessing program alumni advancement, a simple survey item, similar to that which is depicted in Figure 14, which has been abbreviated, can be used to collect data. Once the data are compiled, the summary data can be compared to the national and state wage figures—see Table 1.

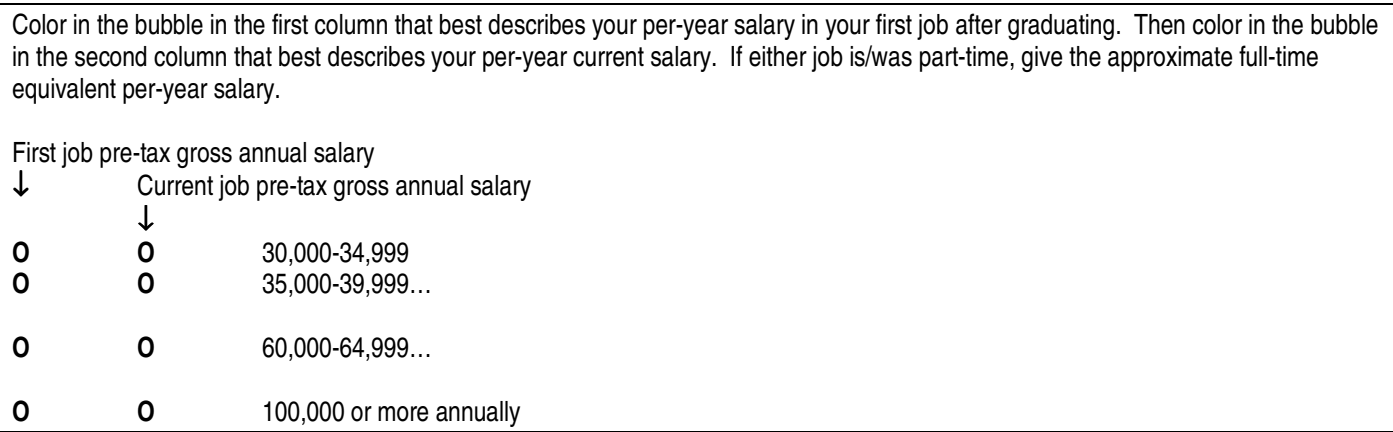

Figure 14. Sample Survey Item for Assessing Program Alumni Advancement

\section{Conclusion}

The purpose of this study was to examine selected sources of instructional and occupational information for their potential to produce and validate statements that describe (a) the expected accomplishments of engineering technology graduates during the first few years after graduation, or objectives and (b) what engineering technology students are expected to know and be able to do upon fulfilling their graduation requirements, or outcomes. The results indicated that these information sources can serve as valuable and viable adjuncts to other means engineering technology programs use for producing and validating program objectives and outcomes. User enthusiasm for employing what has been advocated as a result of the findings should however be tempered by the findings limitations. The data that support the various descriptors that characterize the industrial engineering technologist originated from and represent a snapshot in time. Furthermore, the descriptors describe what was rather than perhaps what ought to be. 
Finally, the data are also collapsed from numerous sources and may not necessarily reflect a particular economic endeavor or locale.

\section{References}

1. Rogers, G. (n.d.). The Language of Assessment: Humpty Dumpty Had a Great Fall . . . . Retrieved October 14, 2007, from http://www.abet.org/Linked\%20DocumentsUPDATE/Assessment/Assessment\%20Tips3.pdf

2. U.S. Department of Labor, Office of Administrative Law Judges. (n.d.). Dictionary of Occupational Titles (4th Ed., Rev. 1991) - Parts. Retrieved January 17, 2008, from http://www.oalj.dol.gov/PUBLIC/DOT/REFERENCES/DOTPARTS.HTM

3. O*NET Resource Center. (n.d.). About $O * N E T$. Retrieved October 14, 2007, from http://www.onetcenter.org/overview.html

4. O*NET OnLine. (n.d.). Welcome to $O^{*} N E T^{T M}$ OnLine! Retrieved October 14, 2007, from http://online.onetcenter.org/

5. Bureau of Labor Statistics. (2007). Standard Occupational Classification (SOC) System. Retrieved June 14, 2007, from http://www.bls.gov/soc/

6. National Crosswalk Service Center. (2002). Metadata ID No. 7, Retrieved May 25, 2006, from http://www.Xwalkcenter.org/readme/7readme.html

7. National Crosswalk Service Center. (n.d.). Crosswalk Information. Retrieved June 11, 2007, from http://www.xwalkcenter.org/xwxwalk.html

8. National Center for Education Statistics. (2002). Classification of Instructional Programs: 2000 edition, Retrieved May 25, 2006, from http://nces.ed.gov/pubsearch/pubsinfo.asp?pubid=2002165

9. O*NET OnLine. (n.d.). Find Occupations. Retrieved October 14, 2007, from http://online.onetcenter.org/find/

10. Pennsylvania Workforce Development. (2007). CIP to SOC Crosswalk File. Retrieved January 13, 2008, from http://www.paworkforce.state.pa.us/professionals/lib/professionals/hpo/2007/cip_soc_2007. pdf 